\title{
Plantas daninhas como hospedeiras alternativas para Pratylenchus brachyurus
}

\author{
Guilherme Braga Pereira Braz ${ }^{1}$, Rubem Silvério de Oliveira Jr. ${ }^{2}$, Jamil Constantin², Ricardo Travasso Raimondi \\ Lilianne Martins Ribeiro ${ }^{4}$, Alexandre Gemelli ${ }^{5}$, Hudson Kagueyama Takano ${ }^{3}$
}

${ }^{1}$ Pós-doutorando Júnior (CNPq) no Núcleo de Estudos Avançados em Ciência das Plantas Daninhas (NAPD) da Universidade Estadual de Maringá (UEM). CEP: 87.020-900, Maringá - PR; ${ }^{2}$ Professor do Departamento de Agronomia (DAG) da Universidade Estadual de Maringá (UEM); ${ }^{3}$ Mestrando no Programa de Pós-graduação em Agronomia (PGA) da Universidade Estadual de Maringá (UEM); ${ }^{4}$ Pós-doutoranda na Universidade de Rio Verde (UniRV); ${ }^{5}$ Doutorando no Programa de Pós-graduação em Agronomia (PGA) da Universidade Estadual de Maringá (UEM) Autor para correspondência: (guilhermebrag@gmail.com)

Data de chegada: 23/09/2015. Aceito para publicação em: 30/05/2016.

$10.1590 / 0100-5405 / 2129$

\section{RESUMO}

Braz, G.B.P.; Oliveira Jr., R.S.; Constantin, J.; Raimondi, R.T.; Ribeiro, L.M.; Gemelli, A.; Takano, H.K. Plantas daninhas como hospedeiras alternativas para Pratylenchus brachyurus. Summa Phytopathologica, v.42, n.3, p.233-238, 2016.

Uma das ações indiretas exercidas pelas plantas daninhas na interferência sob espécies cultivadas é o potencial de hospedar agentes causadores de enfermidades. O nematoide das lesões radiculares (Pratylenchus brachyurus) vem causando uma série de danos em diversas culturas no Brasil. Para o manejo deste fitoparasita, o cultivo de diferentes espécies de crotalárias tem sido empregado. O objetivo deste trabalho foi avaliar a hospedabilidade de plantas daninhas para P. brachyurus, bem como o efeito de supressão de diferentes espécies de crotalária. Para isso, foi instalado um experimento em casa de vegetação no delineamento inteiramente casualizado em arranjo fatorial $(2 \times 17)$, com seis repetições. O primeiro fator consistiu na presença ou ausência da inoculação do nematoide. $\mathrm{O}$ segundo correspondeu a dezessete espécies vegetais, sendo onze plantas daninhas, quatro crotalárias (C. breviflora, C. juncea, C. ochroleuca e $C$ spectabilis) e duas variedades de soja, as quais serviram como testemunha sendo hospedeiras de P. brachyurus. A inoculação do nematoide das lesões radiculares não influenciou a altura de plantas e massa seca de parte aérea das diferentes espécies avaliadas. Portulaca oleracea, Amaranthus viridis e Sida rhombifolia foram as espécies com maior número de nematoides por sistema radicular, e apenas a $S$. rhombifolia apresentou comportamento semelhante a testemunha (variedade de soja BMX Potência $R^{\circledR}{ }^{\circledR}$ ). Com relação ao número de nematoides por grama de raiz, os maiores valores foram observados para A. viridis, seguido por P. oleracea. Excluindo-se a C. juncea, todas as demais espécies de crotalária apresentaram-se como boas opções para o manejo em áreas infestadas com P. brachyurus.

Palavras-chave: Interferências indiretas de plantas daninhas, fitonematoides, nematoide das lesões radiculares.

\section{ABSTRACT}

Braz, G.B.P.; Oliveira Jr., R.S.; Constantin, J.; Raimondi, R.T.; Ribeiro, L.M.; Gemelli, A.; Takano, H.K. Weeds as alternative hosts for Pratylenchus brachyurus. Summa Phytopathologica, v.42, n.3, p.233-238, 2016.

One of the indirect actions of weeds in interfering in cultivated species is their potential to host causative agents of diseases. The root-lesion nematode (Pratylenchus brachyurus) has caused a series of damages to several crops in Brazil. For the management of this plant parasite, cultivation of different Crotalaria species has been used. The aim of this study was to evaluate the host status of weeds to P. brachyurus, as well as the suppressive effect of different Crotalaria species. An experiment was installed under greenhouse conditions in completely randomized design, in factorial arrangement (2x17), with six replicates. The first factor consisted in the presence or absence of nematode inoculation. The second one corresponded to seventeen plant species, of which eleven were weeds, four were Crotalaria species (C. breviflora, C. juncea, $C$. ochroleuca and C. spectabilis), and two were soybean varieties, which were used as control and were hosts of P. brachyurus. Inoculation of the root-lesion nematode did not influence the plant height and the aboveground dry mass of the different evaluated species. Portulaca oleracea, Amaranthus viridis and Sida rhombifolia consisted in the species with larger number of nematodes per root system, and only $S$. rhombifolia showed behavior similar to that of the control (soybean variety $\mathrm{BMX}$ Potência $\mathrm{RR}^{\circledR}$ ). In relation to the number of nematodes per gram of root, the higher values were observed for $A$. viridis, followed by P. oleracea. Excluding C. juncea, all the remaining Crotalaria species showed to be good options for the management in areas infested by P. brachyurus.

Keywords: Indirect weed interference, phytonematodes, root-lesion nematode.

Desde o início da agricultura e da pecuária, as plantas que infestavam espontaneamente as áreas de ocupação humana e que não tinham utilização, eram consideradas indesejáveis e recebiam o conceito de plantas daninhas. Nos ecossistemas agrícolas, a comunidade infestante frequentemente leva vantagem competitiva sobre as plantas cultivadas com interesse econômico. Isso ocorre porque as plantas daninhas apresentam características como elevada taxa de crescimento, grande capacidade reprodutiva e elevada capacidade de exploração de nutrientes do solo, assegurando a sobrevivência em locais perturbados (4).

A convivência das plantas daninhas com a espécie de interesse econômico causa diversos prejuízos, estando estes relacionados à ação direta da comunidade infestante, como competição por recursos (água, nutrientes, luz, espaço físico), alelopatia, intoxicação de animais, e 
ainda, pela ação indireta, por atuarem como hospedeiras de pragas e doenças (13). Entre os diferentes agentes causadores de doenças que as plantas daninhas podem hospedar, destacam-se os nematoides, que são microrganismos multicelulares que colonizam as plantas promovendo danos como a destruição do sistema radicular, formação de nodulações ou lesões necróticas nas raízes, limitando a absorção de água e nutrientes (17).

As plantas daninhas podem se comportar de maneira distinta com relação a hospedabilidade dos nematoides, podendo esta ser mensurada pelo cálculo do fator de reprodução (FR). Quando uma planta daninha apresenta FR de nematoides superior a 1, isto implica que a sua presença resulta na multiplicação dos nematoides, levando ao aumento da população do parasita. De maneira análoga, quando o FR é inferior a 1, a planta daninha em questão apresenta barreiras ao processo de infecção do nematoide, fazendo com que a população deste parasita seja reduzida. Algumas espécies de plantas daninhas apresentam liberação de substâncias químicas (alelopatia) que podem influenciar no desenvolvimento dos nematoides (14).

Entre os principais nematoides que tem causado prejuízos em áreas agrícolas no Brasil, destaca-se o nematoide das lesões radiculares ( $P$. brachyurus), que se caracteriza por ser polífago, endoparasita migratório, promovendo a destruição das células do sistema radicular das plantas atacadas. Poucos trabalhos foram desenvolvidos para avaliar o potencial das plantas daninhas em hospedar o $P$. brachyurus, porém, para outras espécies de nematoides há maior número de relatos.

Em espécies frutíferas é muito comum a ocorrência de nematoides, sendo que estes podem estar associados às plantas daninhas presentes no pomar, pois o manejo da comunidade infestante neste tipo de cultivo é dificultado pelo limitado controle cultural exercido pelas espécies arbóreas. Em trabalho realizado no Estado do Paraná, verificou-se a presença de nematoide, espécie Meloidogyne mayaguensis (sinonímia M. enterolobii), associado a plantas daninhas (picão-preto e caruru) em pomares de goiabeira (2). No cultivo de goiaba, o problema com nematoides formadores de galha é comum, sendo relatada em outro trabalho a espécie $M$. enterolobii associada tanto à goiabeira como às plantas daninhas (1).

O nematoide reniforme (Rotylenchulus reniformis) é outro que apresenta ampla distribuição no Brasil, em função de apresentar vários hospedeiros que são cultivados em quase todas as regiões (18). Foi relatada a ocorrência deste nematoide em diversas plantas daninhas como Euphorbia heterophylla, Bidens pilosa, Commelina diffusa, Portulaca oleracea e Parthenium hysterophorus (12). Estas plantas daninhas são de grande ocorrência em culturas anuais no Brasil, o que faz com que o $R$. reniformis consiga manter sua população ativa no período de entressafra.

Em outro trabalho realizado para avaliar a suscetibilidade de 21 espécies de plantas daninhas ao nematoide de cisto da soja (Heterodera glycines), os autores concluíram a especificidade deste quanto ao hospedeiro, onde em nenhuma das plantas daninhas foram encontradas fêmeas do nematoide (5). Para o H. glycines, os machos após atingirem o estágio adulto abandonam as raízes, sendo as fêmeas que apresentam capacidade infectiva. Desta forma, a presença das fêmeas de $H$. glycines nas raízes de uma espécie vegetal indica potencial da mesma em hospedar o nematoide de cisto da soja.

Em função da escassez de informações quanto ao potencial de plantas daninhas em hospedar P. brachyurus, torna-se necessário a realização de estudos com este objetivo, visto que os resultados poderão indicar práticas para o manejo do nematoide. Neste contexto, o objetivo do presente trabalho foi avaliar quais espécies de plantas daninhas apresentam-se como hospedeiras do nematoide das lesões radiculares, bem como o potencial efeito nematicida de quatro espécies de crotalária.

\section{MATERIAL E MÉTODOS}

O experimento foi conduzido em casa de vegetação no Centro de Treinamento em Irrigação (CTI) da Universidade Estadual de Maringá (UEM) (2324'12"S e 51 ${ }^{\circ} 56^{\prime} 24^{\prime \prime} \mathrm{O}$ e altitude de $\left.560 \mathrm{~m}\right)$. O período de condução dos ensaios foi de 08/01/2015 a 08/04/2015.

Para assegurar que não houvesse a presença de outros nematoides no solo utilizado no experimento, foi realizada a esterilização deste material, por meio da solarização (9). Inicialmente, o solo foi peneirado e colocado sobre lona plástica, fazendo uma camada de $20 \mathrm{~cm}$ de altura, sendo posteriormente levemente umedecido sem deixar encharcar. Após este procedimento, o solo foi coberto por lona plástica transparente, afim de elevar-se a temperatura interna pela exposição ao sol. Após seis semanas nesta condição, o solo foi descoberto e utilizado no preenchimento das unidades experimentais, as quais consistiam em vasos com capacidade para $6 \mathrm{dm}^{3}$.

A análise de solo revelou as seguintes características químicas e físicas: $\mathrm{pH}$ em água de 5,30;3,30 $\mathrm{cmol}_{\mathrm{c}} \mathrm{dm}^{-3} \mathrm{de}^{+}+\mathrm{Al}^{+3} ; 0,90 \mathrm{cmol}_{\mathrm{c}}$

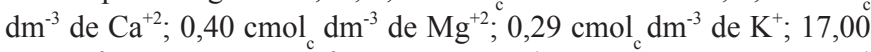
$\mathrm{mg} \mathrm{dm}{ }^{-3}$ de P; $10,00 \mathrm{~g} \mathrm{dm}^{-3}$ de C; $568 \mathrm{~g} \mathrm{~kg}^{-1}$ de areia grossa; $171 \mathrm{~g} \mathrm{~kg}^{-1}$ de areia fina; $56 \mathrm{~g} \mathrm{~kg}^{-1}$ de silte e $205 \mathrm{~g} \mathrm{~kg}^{-1}$ de argila (textura franco argilo-arenosa).

O delineamento experimental utilizado foi inteiramente casualizado (DIC), com seis repetições. O experimento foi conduzido em arranjo fatorial $(2 \times 17)$, sendo os níveis do primeiro fator constituídos pela inoculação do nematoide ( $P$. brachyurus) ou ausência desta. Os níveis do segundo fator foram constituídos das espécies vegetais avaliadas, totalizando dezessete tratamentos (Tabela 1). O critério utilizado na escolha das 11 espécies de plantas daninhas foi a importância relativa que cada uma apresenta como infestante. Adicionalmente, foram avaliadas quatro espécies de crotalária, com o objetivo de verificar o comportamento de nematoide em cada uma delas e duas variedades de soja que serviram de testemunha para assegurar que a inoculação tivesse sido realizada corretamente, visto que esta espécie é reconhecidamente suscetível ao nematoide das lesões radiculares (10).

A semeadura de todas as espécies foi realizada em 29/12/2014, posicionando as sementes a $1-2 \mathrm{~cm}$ de profundidade em cada vaso. Após a semeadura das espécies os vasos foram mantidos em casa de vegetação e irrigados diariamente com lâminas variando de 5 a $10 \mathrm{~mm}$ até o final do experimento. Após a emergência das plantas daninhas, efetuou-se o desbaste, deixando-se duas plântulas por vaso. Os vasos foram mantidos livres da presença de outras plantas que não fossem as avaliadas no tratamento.

O inóculo de P. brachyurus utilizado foi proveniente de vasos cultivados com sorgo no município de Rio Verde - GO. Para obtenção dos nematoides, em laboratório, as raízes de sorgo infectadas foram lavadas, cortadas em pedaços de aproximadamente um centímetro e trituradas pela técnica do liquidificador, aliada a centrifugação em solução de sacarose, seguindo o método de Coolen e D'Herde (3). Na suspensão obtida, foi estimado o número de espécimes do nematoide por mililitro com o auxílio de microscópio óptico e lâmina de Peters, sendo realizada a contagem em quatro amostras, adotando-se o valor médio entre estas.

No décimo dia após a semeadura das plantas daninhas realizou-se a inoculação dos nematoides nas diferentes espécies. Para isso, foram 
Tabela 1. Relação das espécies avaliadas no experimento. Maringá, PR -2015.

\begin{tabular}{lcc}
\hline Nome comum & Nome científico & Família \\
\hline Crotalária & Crotalaria breviflora & \\
Crotalária & Crotalaria juncea & \\
Crotalária & Crotalaria ochroleuca & \\
Crotalária & Crotalaria spectabilis & Fabaceae \\
Fedegoso & Senna obtusifolia & \\
Soja (M 6210 IPRO ${ }^{\circledR}$ ) & Glycine max & \\
Soja (BMX Potência $\mathrm{RR}^{\circledR}$ ) & Glycine max & \\
\hline Picão-preto & Bidens pilosa & Asteraceae \\
\hline Beldroega & Portulaca oleracea & Portulacaceae \\
\hline Caruru-de-mancha & Amaranthus viridis & Amaranthaceae \\
\hline Guanxuma & Sida rhombifolia & Malvaceae \\
\hline Trapoeraba & Commelina benghalensis & Commelineaceae \\
\hline Corda-de-viola & Ipomoea grandifolia & Convolvulaceae \\
\hline Capim pé-de-galinha & Eleusine indica & \\
Capim-carrapicho & Cenchrus echinatus & \\
Capim-braquiária & Brachiaria decumbens & Poaceae \\
Capim-marmelada & Brachiaria plantaginea & \\
\hline
\end{tabular}

realizados dois orifícios a $2 \mathrm{~cm}$ de profundidade no solo e distanciados de $1 \mathrm{~cm}$ do colo de cada plântula. Em cada um deles, adicionou-se 10 $\mathrm{mL}$ da suspensão de nematoides, previamente calibrada, perfazendo uma população inicial (Pi) de 1000 nematoides por plântula, num total de 2000 espécimes por vaso.

Aos 90 dias após a inoculação (DAI) foram realizadas avaliações afim de se verificar o efeito dos nematoides sobre o crescimento das plantas. Para a avaliação de altura de plantas, mediu-se a altura desde a superfície do solo contido no vaso até a inserção da última folha completamente expandida, sendo esta medição realizada apenas para as espécies dicotiledôneas, exceto pela corda-de-viola (I. grandifolia). Para determinar a massa seca de parte aérea das plantas (MSPA), estas foram retiradas cuidadosamente dos vasos e a parte aérea separada do sistema radicular, fazendo a secagem deste material em estufa de circulação forçada de ar, na qual as plantas permaneceram durante o período de 72 horas em temperatura média de $65^{\circ} \mathrm{C}$, sendo posteriormente realizada a pesagem para a obtenção da MSPA.

Nos vasos em que foi realizada a inoculação dos nematoides também foi avaliada a massa fresca das raízes (MFR) e população do nematoide. Os sistemas radiculares foram lavados em água corrente, as raízes sobrepostas em papel absorvente até a eliminação do excesso de água, em seguida foram pesadas e obteve-se a MFR.

Para obtenção da população de nematoides das raízes, estas foram cortadas e trituradas por 30 segundos com o auxílio de um liquidificador, segundo a técnica de Coolen e D'Herde (3). Em seguida, a população final (Pf) de $P$. brachyurus foi quantificada na suspensão de cada parcela (repetição do tratamento) com o auxílio de lâmina de Peters e microscópio de objetiva invertida. Após obtenção dos dados, determinou-se o número total de $P$. brachyurus (raiz) $(\mathrm{TN})$, número de P. brachyurus por grama de raiz (NGR) e o fator de reprodução (FR), dividindo-se a Pf pela Pi, conforme Oostenbrink (15).

As análises estatísticas foram realizadas com o programa computacional Sisvar (7). Os dados foram submetidos à análise de variância pelo teste F. Quando foram observados efeitos significativos procedeu à comparação das médias pelo teste de Fisher's LSD $(p \leq 0,05)$.

\section{RESULTADOS E DISCUSSÃO}

Na Tabela 2 estão apresentados os resultados para as avaliações de massa seca de parte aérea e altura de plantas para as diferentes espécies submetidas à inoculação do nematoide das lesões radiculares. Para ambas as variáveis analisadas, não foram observadas diferenças entre as plantas que se desenvolveram na presença do nematoide e as livres destes fitoparasitas. As diferenças encontradas estão relacionadas apenas ao crescimento diferencial que cada uma das espécies avaliadas apresenta.

Resultados já descritos na literatura também corroboram com os obtidos no presente trabalho no que diz respeito ao efeito dos nematoides nestas variáveis analisadas (8). Uma possível explicação para este comportamento, com o que é visualizado em plantas que se desenvolvem a campo em áreas infestadas por nematoides é que em casa de vegetação as condições de crescimento das plantas são ótimas, não havendo limitação de recursos. Nas lavouras, o dano provocado pelo nematoide ao sistema radicular, associado a condições limitantes como por exemplo um período de déficit hídrico, tende a comprometer o crescimento da parte aérea da cultura e por isso são comumente visualizadas plantas com porte reduzido.

Comparando o crescimento das quatro espécies de crotalária, fica evidente que as com maior porte de plantas são $C$. juncea e $C$. ochroleuca, seguida por C. spectabilis. A C. breviflora foi a que apresentou menor altura e massa seca de parte aérea. Tendo em vista que estas espécies são utilizadas como culturas de cobertura em áreas infestadas por nematoides, a maior quantidade de biomassa produzida é benéfica para as áreas em que são cultivadas, pois quando decomposto, este material vegetal pode liberar substâncias que atuaram na supressão da população dos fitoparasitas.

$\mathrm{Na}$ Tabela 3 estão apresentados os resultados referentes às avaliações de hospedabilidade de diferentes espécies vegetais ao nematoide das lesões radiculares ( $P$. brachyurus). Os maiores valores de massa fresca de raiz (MFR) foram observados para o capim pé-degalinha (E. indica), seguidos por trapoeraba ( $C$. benghalensis), duas espécies de crotalária ( $C$. juncea e $C$. ochroleuca) e a variedade de soja BMX Potência RR ${ }^{\circledR}$.

O volume de raiz que uma espécie vegetal possui tem relação direta com o comportamento populacional dos nematoides, visto que um sistema radicular maior apresenta capacidade superior de exploração do solo e desta forma aumenta-se a possibilidade do fitoparasita alimentar-se da raiz e multiplicar sua população. Apesar disto, do ponto de vista prático, uma das medidas adotadas para se reduzir os danos provocados pelos nematoides é a utilização de produtos que conferem maior desenvolvimento radicular, pois plantas com maiores volumes de raízes tendem a apresentar menor sensibilidade aos danos provocados por estes parasitas (19). Ressalta-se, porém que, além do aspecto físico relacionado ao volume total de raízes, fatores relacionados à morfologia (composição do tecido das raízes) e à fisiologia (liberação de compostos de defesa) da planta também serão determinantes para que haja ou não o processo de infecção do nematoide.

Entre as dezessete espécies vegetais avaliadas, oito apresentaram nematoides recuperados quando procedida a extração do sistema radicular (Tabela 3). Os maiores números de nematoides por sistema radicular (TN) foram observados para C. juncea, S. rhombifolia e a variedade de soja BMX Potência $R^{\circledR}$, seguido pela variedade M 6210 IPRO $^{\circledR}$. A. viridis foi outra planta daninha que apresentou elevado número de nematoides extraídos das raízes. Para P. oleracea, B. pilosa e I. grandifolia, houve a recuperação de um baixo número de nematoides, especialmente para as duas últimas espécies. Não foram recuperados 
Tabela 2. Efeito do nematoide das lesões radiculares (P. brachyurus) sobre massa seca da parte aérea (MSPA) e a altura de plantas (AP) sob diferentes espécies vegetais aos 90 dias após a inoculação. Maringá, PR - 2015.

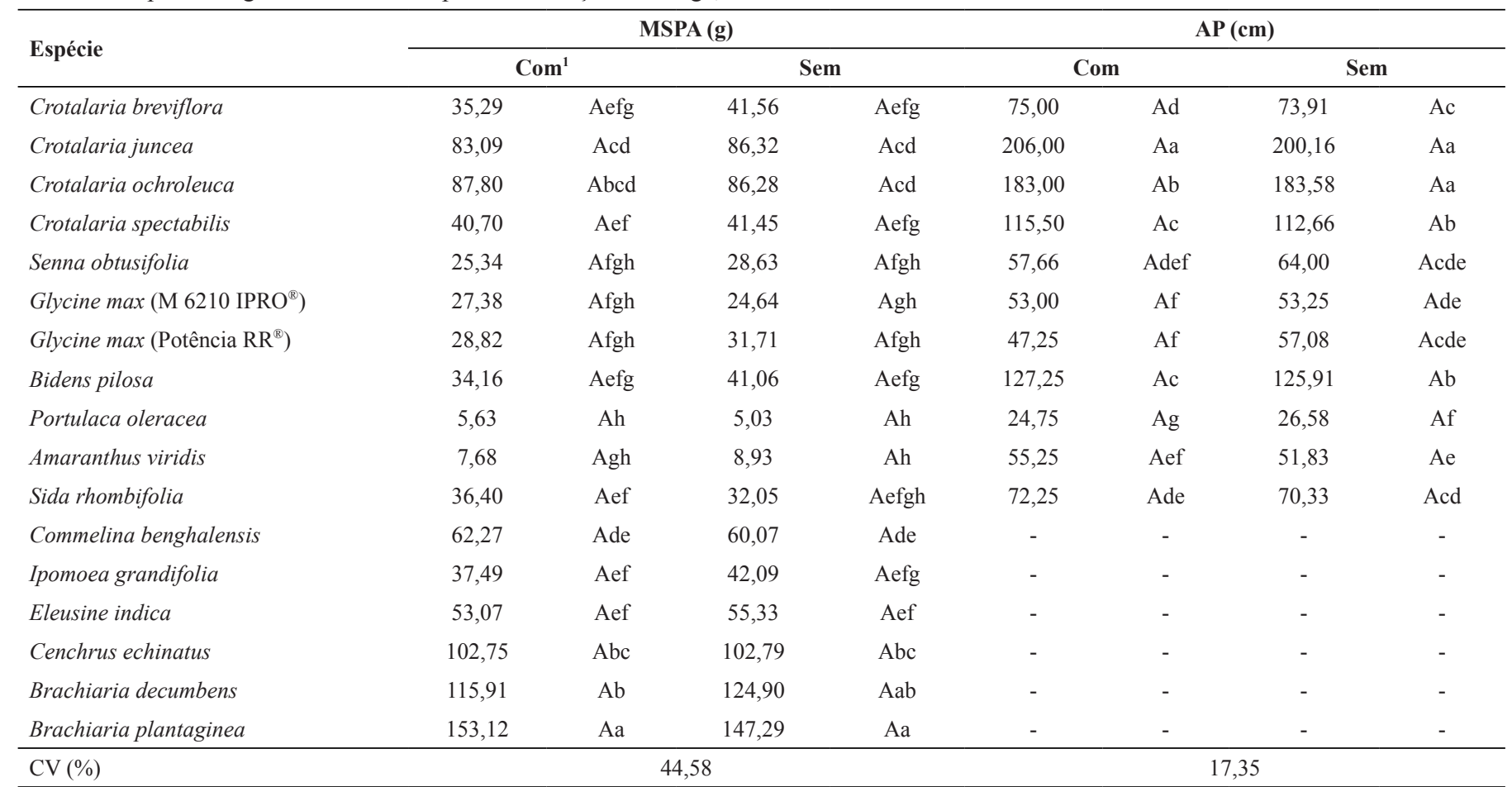

${ }^{1}$ Com - Plantas submetidas à inoculação do nematoide; Sem - Plantas não submetidas à inoculação do nematoide. Médias seguidas por letras maiúsculas distintas na linha e seguidas por letras minúsculas na coluna diferem pelo teste Fisher's LSD $(\mathrm{p} \leq 0,05)$.

Tabela 3. Massa fresca de raiz (MFR), total de nematoides por sistema radicular (TN), número de nematoides por grama de raiz (NGR) e fator de reprodução (FR) de P. brachyurus aos 90 dias após a inoculação em diferentes espécies vegetais. Maringá, PR - 2015.

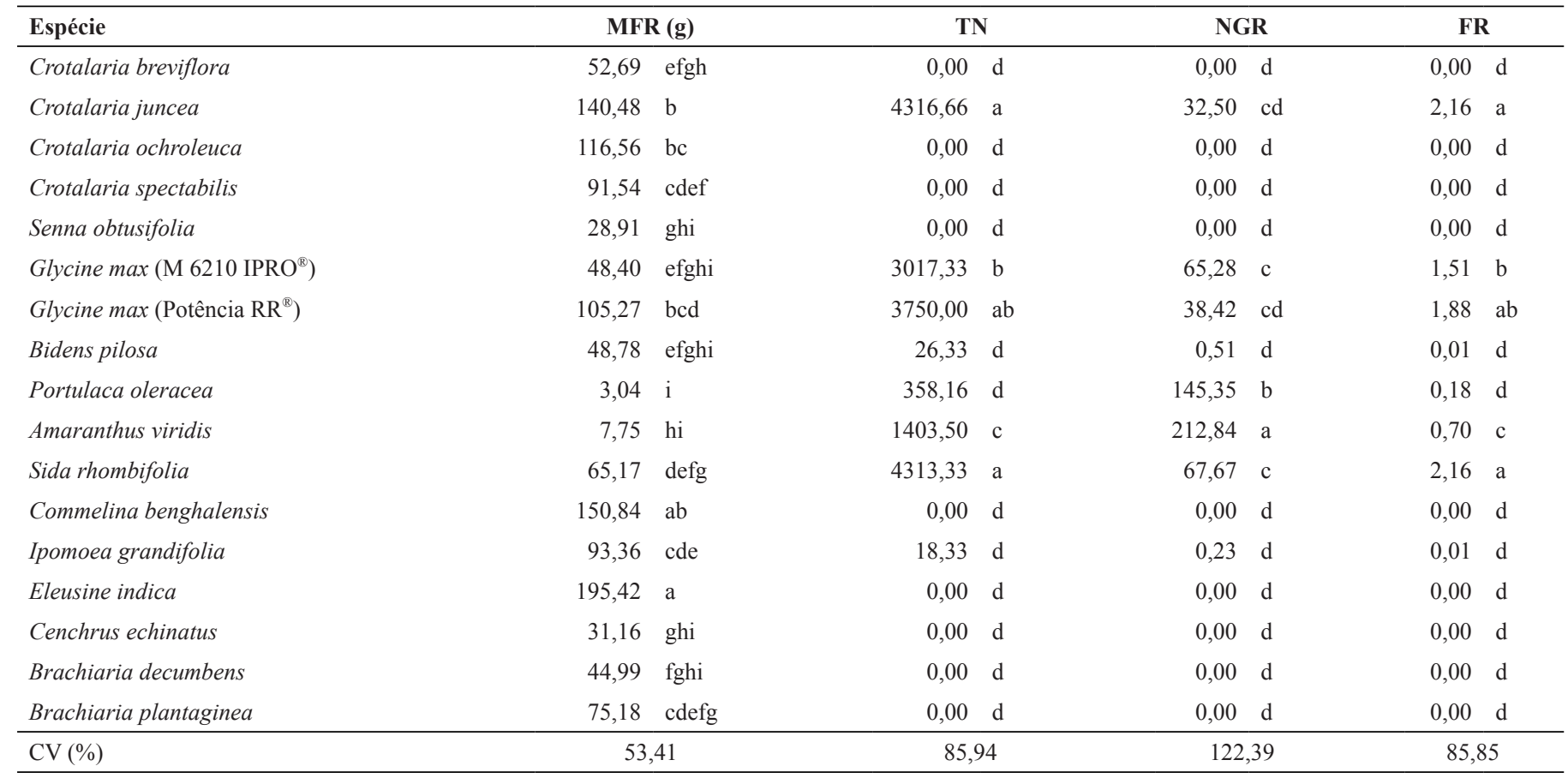

Médias seguidas pela mesma letra nas colunas, não diferem entre si pelo teste Fisher's LSD ( $\mathrm{p} \leq 0,05)$.

nematoides nas outras plantas daninhas avaliadas, bem como nas outras três espécies de crotalária (C. breviflora, C. ochroleuca e C. spectabilis).

Outra variável analisada foi o número de nematoides por grama de raiz (NGR), que serve como indicativo para avaliar a densidade populacional do parasita no interior do sistema radicular. A vantagem desta variável é que em seu cálculo são englobados tanto a MFR quanto o TN, e desta forma representa uma estimativa mais concisa em relação ao comportamento de hospedeira de uma planta para o nematoide. 
O maior valor de NGR foi observado no tratamento com cultivo de $A$. viridis, seguido por $P$. oleracea (Tabela 3). Estes resultados demonstram a importância de se avaliar o NGR, uma vez que observando apenas os dados do $\mathrm{TN}$, estas duas espécies não se destacaram como aquelas com potencial de hospedar maior número de nematoides. A explicação para estes resultados está relacionada à massa do sistema radicular de ambas as espécies, que é bem menor quando comparada à das plantas em que foram observados maiores valores de TN (C. juncea e S. rhombifolia).

Para o número total de nematoides de $C$. juncea, observa-se que esta espécie apresenta um dos maiores valores para a variável, porém, quando é analisado o NGR, são registrados os menores valores entre as plantas que apresentaram nematoides recuperados. $\mathrm{O}$ fato pode ser explicado pela grande massa de raiz que esta espécie de crotalária apresenta, fato que possibilitou uma maior multiplicação dos nematoides. Apesar de $C$. juncea não ter apresentado resultados que a credenciam como cultura de cobertura para o manejo em áreas infestadas por P. brachyurus como as outras espécies deste gênero avaliadas, é importante destacar que já foi comprovada a sua eficiência na supressão de outros nematoides (11).

C. juncea e S. rhombifolia apresentaram os maiores valores de FR, não diferindo estatisticamente da variedade de soja BMX Potência $\mathrm{RR}^{\circledR}$ (Tabela 3). Um exemplo para melhor entendimento do que o FR representa é o seguinte, em uma área infestada com $P$. brachyurus e em que há predominância de $S$. rhombifolia na composição da comunidade infestante, após 90 dias da emergência desta planta daninha, a população do nematoide poderá aumentar em valores próximos a 2,16 em relação a população inicial. Evidentemente, há outras variáveis que vão influenciar o comportamento populacional do nematoide, bem como dificilmente haverá área em que há apenas a presença de uma espécie daninha.

A soja M 6210 IPRO $^{\circledR}$ apesar de ter apresentado FR significativamente menor do que da $C$. juncea e $S$. rhombifolia, quando comparado com a outra variedade desta oleaginosa apresentou valores similares. Estes resultados demonstraram que em termos de manejo varietal visando a semeadura em áreas infestadas por P. brachyurus, ambas as variedades de soja vão apresentar comportamento semelhante, não sendo resistentes ao fitonematoide.

A. viridis apresentou FR igual a 0,70, o que implicaria em dizer que é uma espécie que reduz a população de nematoides no solo. Apesar disto, estes dados devem ser analisados com cuidado, pois entre todas as espécies avaliadas, foi a que apresentou maior número de nematoides por grama de raiz. Isso ocorreu devido ao baixo desenvolvimento das raízes de $A$. viridis em condições de casa de vegetação, o que subestimou o potencial desta espécie em hospedar os nematoides, fato que no campo não é comumente observado. Este comportamento observado para $A$. viridis com relação a hospedabilidade de $P$. brachyurus também pode ser atribuído a $P$. oleracea.

Em trabalho descrito na literatura, foi relatado que o capimbraquiária (B. decumbens) é uma espécie hospedeira do nematoide das lesões radiculares, apresentando FR igual a 1,8 (6). Estes dados não corroboram com o presente trabalho, onde para a mesma espécie vegetal não foi recuperado nenhum nematoide no processo de extração. Uma possível explicação para esta divergência está relacionada a metodologia utilizada em ambos os trabalhos. No presente não foi quantificada a população de nematoides no solo e no desenvolvido por Dias-Arieira et al. (6) foi realizada a extração das raízes e do solo. Isto fica mais evidente quando se observa a proporção de nematoides provenientes das raízes e do solo na composição da população final, onde uma fração de $87,44 \%$ foi recuperada do ambiente edáfico.

Outra possível explicação para ter sido verificada a divergência nos resultados do presente experimento e o supracitado está relacionada a variabilidade de biótipos existente dentro de uma mesma espécie. Na literatura já foi relatada para o gênero Brachiaria sp. um biótipo que se portou como suscetível ao P. brachyurus e outro que se apresentou como moderadamente resistente, pertencendo ambos a mesma espécie vegetal (16).

Entre as diferentes espécies de crotalária, excluindo-se a $C$. juncea, todas as outras apresentaram potencial para serem utilizadas na supressão do nematoide das lesões radiculares. Os dados observados no presente trabalho para estas espécies corroboram com os descritos por Inomoto et al. (10), onde além de apresentarem-se como plantas não hospedeiras de $P$. brachyurus, $C$. breviflora e $C$. spectabilis também foram antagonistas para o nematoide de galhas (Meloidogyne javanica).

Com os resultados observados neste trabalho, fica ainda mais evidente a importância de se controlar as plantas daninhas, visto que além dos danos causados pela matocompetição, estas podem atuar como hospedeiras de nematoides. Mesmo em áreas cultivadas com culturas como $C$. spectabilis, onde normalmente não são adotadas medidas de controle de plantas daninhas, é fundamental que se adote algum manejo sobre a comunidade infestante, visto que estas poderão hospedar os fitoparasitas e comprometer o objetivo do cultivo da espécie de cobertura para supressão de nematoides.

A inoculação do nematoide das lesões radiculares não influenciou a altura de plantas e massa seca de parte aérea das diferentes espécies avaliadas.

Em ordem crescente, $P$. oleracea, A. viridis e S. rhombifolia consistiram nas espécies de plantas daninhas com maior número total de nematoides por sistema radicular, sendo apenas a $S$. rhombifolia semelhante à testemunha (variedade de soja BMX Potência $R^{\circledR}$ ).

Com relação ao número de nematoides por grama de raiz, os maiores valores foram observados para $A$. viridis, seguido por $P$. oleracea.

Excluindo-se a $C$. juncea, todas as demais espécies de crotalária apresentaram-se como boas opções para o manejo em áreas infestadas com P. brachyurus.

\section{AGRADECIMENTOS}

Ao CNPq, pelo financiamento do experimento através do Edital MCTI/CNPq 14/2013 - Universal.

\section{REFERÊNCIAS}

1. Almeida, E.J.; Alves, Gleina, C.S.; Santos, J.M.; Martins, A.B.G. Assinalamentos de Meloidogyne enterolobii em goiabeira e em plantas invasoras no Estado de São Paulo, Brasil. Nematologia Brasileira, Piracicaba, v.35, n.1-2, p.50-52, 2011.

2. Carneiro, R.G.; Mônaco, A.P.A.; Moritz, M.P.; Nakamura, K.C.; Scherer, A. Identificação de Meloidogyne mayaguensis em goiabeira e em plantas invasoras, em solo argiloso, no Estado do Paraná. Nematologia Brasileira, Piracicaba, v.30, n.3, p.293-298, 2006.

3. Coolen, W.A.; D'Herde, C.J. A method for the quantitative extraction of nematodes from plant tissue. Ghent: State Agriculture Research Center, 1972. 77p.

4. Cury, J.P.; Santos, J.B.; Silva, E.B.; Byrro, E.C.M.; Braga, R.R.; Carvalho, F.P.; Valadão Silva, D. Acúmulo e partição de nutrientes de cultivares de milho em competição com plantas daninhas. Planta Daninha, Viçosa, MG, 
v.30, n.2, p.287-296, 2012.

5. Dias, W.P.; Ferraz, S.; Silva, A.A.; Lima, R.D.; Valle, L.A.C. Hospedabilidade de algumas ervas daninhas ao nematóide de cisto da soja. Nematologia Brasileira, Piracicaba, v.19, n.1-2, p.9-14, 1995.

6. Dias-Arieira, C.R.; Ferraz, S.; Ribeiro, R.C.F. Reação de gramíneas forrageiras a Pratylenchus brachyurus. Nematologia Brasileira, Piracicaba, v.33, n.1, p.90-93, 2009.

7. Ferreira, D.F. Sisvar: a computer statistical analysis system. Ciência e Agrotecnologia, Lavras, v.35, n.6, p.1039-1042, 2011.

8. Furlanetto, C.; Davi, J.J.S.; Grabowski, M.M.S.; Dias-Arieira, C.R.; Layter, N.A.; Seifert, K.E. Reação de adubos verdes de verão ao nematóide Tubixaba tuxaua. Tropical Plant Pathology, Brasília, v.33, n.6, p.403-408, 2008.

9. Ghini, R. Desinfestação do solo com o uso de energia solar: solarização e coletor solar. Jaguariúna: EMBRAPA-CNPMA, 1997. 29p. (EMBRAPA-CNPMA. Circular Técnica, 1).

10. Inomoto, M.M.; Motta, L.C.C.; Beluti, D.B.; Machado, A.C.Z. Reação de seis adubos verdes a Meloidogyne javanica e Pratylenchus brachyurus. Nematologia Brasileira, Piracicaba, v.30, n.1, p.39-44, 2006.

11. Inomoto, M.M.; Antedomênico, S.R.; Santos, V.P.; Silva, R.A.; Almeida, G.C. Avaliação em casa de vegetação do uso de sorgo, milheto e crotalária no manejo de Meloidogyne javanica. Tropical Plant Pathology, Brasília, v.33, n.2, p.125-129, 2008.

12. Inserra, R.N.; Dunn, R.A.; Mcsorley, R.; Langdon, K.R.; Richmer, A.Y. Weed hosts of Rotylenchulus reniformis in ornamental nurseries of Southern
Florida. Nematology Circular, Gainesville, n.171, 1989.

13. Kozlowski, L.A. Ronzelli Júnior, P.; Purissimo, C.; Daros, E.; Koehler, H.S. Período crítico de interferência das plantas daninhas na cultura do feijoeiro-comum em sistema de semeadura direta. Planta Daninha, Viçosa, v.20, n.2, p.213-220, 2002

14. Mello, A.F.S.; Machado, A.C.Z.; Inomoto, M.M. Potencial de controle da Erva-de-Santa-Maria sobre Pratylenchus brachyurus. Fitopatologia Brasileira, Brasília, v.31, n.5, p.513-516, 2006.

15. Oostenbrink, M. Major characteristics of the relation between nematodes and plants. Mendelingen Landbouwhogeschool, Wageningen, v.66, n.4, p.1-46, 1966.

16. Queiróz, C.A.; Fernandes, C.D.; Verzignassi, J.R.; Valle, C.B.; Jank, L.; Mallmann, G.; Batista, M.V. Reação de acessos e cultivares de Brachiaria spp. e Panicum maximum à Pratylenchus brachyurus. Summa Phytopathologica, Botucatu, v.40, n.3, p.226-230, 2014.

17. Ritzinger, C.H.S.P.; Fancelli, M. Manejo integrado de nematóides na cultura da bananeira. Revista Brasileira de Fruticultura, Jaboticabal, v.28, n.2, p.331-338, 2006.

18. Soares, P.L.M.; Santos, J.M.; Lehman, P.S. Estudo morfométrico comparativo de populações de Rotylenchulus reniformis (Nemata: Rotylenchulinae) do Brasil. Fitopatologia Brasileira, Brasília, v.28, n.3, p.292-297, 2003.

19. Starr, J.L.; Koenning, S.R.; Kirkpatrick, T.L.; Robinson, A.F.; Roberts, P.A.; Nichols, R.L. The future of nematode management in cotton. Journal of Nematology, Hanover, v.39, n.4, p.283-294, 2007. 